\title{
Efeito da idade relativa nas seleções mundiais de base sub 17 e sub
}

\section{0}

\section{Effect of relative age in the sub-17 and sub-20 world-based selections}

Rodrigo Odair Oliveira Julião ${ }^{1}$, César Milagres da Silva ${ }^{1}$, Wanda Maria Costa Braga ${ }^{1}$, Siomara Aparecida da Silva ${ }^{1 *}$

ARTIGO ORIGINAL | ORIGINALARTICLE

\begin{abstract}
presente estudo objetivou investigar a presença dos Efeitos da Idade Relativa nas seleções de base que participaram dos mundiais sub 17 e sub 20 no ano de 2017. A amostra foi constituída por 462 atletas, sendo 231 da categoria sub 17 e 231 da categoria sub 20. Todos foram divididos por quartis baseados no seu mês de nascimento. Os resultados evidenciam uma consistente superioridade de atletas nascidos nos Q1 e Q2, nas duas categorias, mas com uma pequena migração no número de atletas para Q3 e Q4 na categoria sub 20. Assim, Efeitos da Idade Relativa esteve presente nos dois mundiais de base, sub 17 e sub 20 de 2017, e que não há um critério de seleção que considere por base a data de nascimento, mas sim uma tendência em escolher atletas mais maturados nas categorias de base.

Palavras-chave: futebol, categoria de base, efeito da idade relativa.
\end{abstract}

ABSTRACT

The present study aimed to investigate the presence of Relative Age Effects in the base selections that participated in the sub 17 and sub 20 world cups in the year 2017. The sample consisted of 462 athletes, of whom 231 were sub-17 and 231 were sub-20. All were divided by quartiles based on their birth month Q1 (January-March), Q2 (April-June), Q3 (July-September) and Q4 (October-December). A descriptive analysis of the data was performed. The results show a consistent superiority of athletes born in Q1 and Q2, in both categories, but with a small migration in the number of athletes for Q3 and Q4 in the sub 20 category. We conclude that the Effects of Relative Age was present in the two base world cup, sub 17 and sub 20 of 2017, and that there is no selection criterion based on the date of birth, but rather a tendency to choose more matured athletes in the base categories.

Keywords: football, base category, effect of relative age.

\footnotetext{
${ }^{1}$ Universidade Federal de Ouro Preto, Minas Gerais, Brasil

* Autor correspondente: siomarasilva.lamees@gmail.com
} 


\section{INTRODUÇÃo}

O futebol é o esporte mais praticado no mundo. Só no Brasil, milhões de pessoas vão aos estádios a cada domingo para assistir a uma partida e torcer por seus times, aqui o jogo é conhecido como uma "paixão nacional". Essa paixão atinge também as crianças que não apenas assistem, querem também ser jogadores e jogadoras de futebol, não somente pela profissão, mas também pela ascensão social, porque hoje jogadores de futebol tem status de artistas.

Para se tornar um jogador profissional, todas estas crianças têm de passar por uma longa trajetória e se destacar entre seus pares, para chegar a um bom time de elite e assim, ganhar visibilidade para algum dia chegar a uma seleção de base, o que ajuda muito a se firmar e chegar a ser um jogador profissional. Mas como o que determina quem é bom ou não é seu desempenho, seja em uma peneira, ou seja, já em seu clube, todos esses jovens jogadores sofrem influência dos Efeitos da Idade Relativa (EIR) (Rabelo et al., 2016).

As categorias geralmente são divididas pelo ano de nascimento. $\mathrm{O}$ fenômeno da idade relativa é a diferença maturacional entre indivíduos que compõem a mesma categoria. Há uma vantagem dos que nascem mais próximos do início do ano em relação aos que nascem no final do mesmo ano. Esta diferença pode ser de até 12 meses, e pode chegar a 24 meses dentre na mesma categoria. Se considerada a idade biológica pode ocorrer uma diferença de até 36 meses na maturação (Silva, Padilha \& Costa 2015). Carli, Luguetti, Ré e Böhme (2009) afirma que o EIR ocorre pela diferença dos aspectos físicos, emocionais e intelectuais entre indivíduos de um mesmo grupo. Ribeiro Jr et al. (2013) sustenta que a maturação física precoce como a estatura e acúmulo de massa muscular, tende a facilitar seu desempenho durante a puberdade. Penna e Moraes (2010) afirmam que, principalmente nas idades dos mais jovens, atletas com maior vigor físico terão vantagens com relação aos demais, obtendo as melhores resultados e conquistando seu espaço nas equipes de elite.

O que todos esses autores defendem, é que talvez haja certa distorção no que diz respeito ao objetivo das categorias de base, em que o foco, a princípio, seria na formação de atletas, e não apenas a busca imediatista de um atleta que possa já trazer títulos por sua condição maturacional atual, em detrimento dos que estão em estágios de desenvolvimento inferiores. Penna, Costa, Ferreira e Moraes (2012) apontam que durante o processo de seleção, vários jovens podem ser erroneamente apontados como talentosos por se valerem de seu vigor físico, advindo de uma maturação precoce. E como, normalmente, quem se destaca na peneira é escolhido para o clube, quem se destaca no clube consegue oportunidade nas equipes de elite, e os que se sobressaem nas equipes de elite são convocados para a seleção nacional da categoria. $O$ universo das competições de seleções nacionais foi escolhido para ser analisado o EIR em duas categorias, sub 17 e sub 20.

O objetivo deste trabalho é analisar as seleções que participaram dos dois mundiais de base em 2017, a Copa do Mundo FIFA sub 20, disputada na Coreia do Sul, e a Copa do Mundo FIFA sub 17, disputada na Índia. E verificar primeiramente se o EIR se aplica nesses grupos, se há alguma diferenciação entre as equipes do mesmo país, tomando por base a data de nascimento, para ver se há algum padrão de repetição entre os selecionáveis com relação ao seu mês de natalidade, o que comprovaria uma tendência a escolha dos atletas mais maturados, uma vez que há uma diferença de até três anos entre as categorias.

\section{MÉTODO}

\section{Participantes}

Fizeram parte do estudo os atletas representantes das seleções que participaram dos dois mundiais da FIFA em 2017, são elas: Alemanha, Costa Rica, Estados Unidos, França, Guiné, Honduras, Inglatera, Irã, Japão, México e Nova Zelândia. Totalizando 462 atletas, sendo 231 da categoria sub 17, e 231 da categoria sub 20. Foram analisadas as datas de nascimento de cada um deles, a coleta de dados se fez por pesquisa via internet, no site oficial da FIFA.

\section{Instrumentos e Procedimentos}

Para análise dos dados, os jogadores foram divididos em quartis, cada quartil representando 
três meses do ano. Sendo o primeiro quartil composto pelos meses de janeiro, fevereiro e março. O segundo por abril, maio e junho. O terceiro por julho, agosto e setembro. E o quarto por outubro, novembro e dezembro. A seleção de Guiné é a única representante do continente africano, em que o mês determinante do início de cada categoria, é julho e o calendário se encerra em junho. Então para Guiné, o primeiro quartil será composto por julho, agosto e setembro. $\mathrm{O}$ segundo por outubro, novembro e dezembro. O terceiro por janeiro, fevereiro e março. E o quarto por abril, maio e junho.

\section{RESULTADOS}

Tabela 1

Resultados observados somente na categoria sub 17

\begin{tabular}{ccc}
\hline $1^{\circ}$ Semestre & 151 & $65 \%$ \\
\hline $1^{\circ}$ Quartil & 98 & $42 \%$ \\
\hline $2^{\circ}$ Quartil & 53 & $23 \%$ \\
\hline $2^{\circ}$ Semestre & 80 & $35 \%$ \\
\hline $3^{\circ}$ Quartil & 56 & $25 \%$ \\
\hline $4^{\circ}$ Quartil & 24 & $10 \%$ \\
\hline
\end{tabular}

Tabela 2

Resultados observados somente na categoria sub 20

\begin{tabular}{ccc}
\hline $1^{\circ}$ Semestre & 147 & $64 \%$ \\
\hline $1^{\circ}$ Quartil & 82 & $35 \%$ \\
\hline $2^{\circ}$ Quartil & 65 & $28 \%$ \\
\hline $2^{\circ}$ Semestre & 84 & $36 \%$ \\
\hline $3^{\circ}$ Quartil & 46 & $20 \%$ \\
\hline $4^{\circ}$ Quartil & 38 & $16 \%$ \\
\hline
\end{tabular}

Tabela 3

Frequência absoluta e percentual dos atletas em cada quartil, de acordo com seu mês de nascimento, separados por cada seleção

\begin{tabular}{lcccccccc}
\hline \multicolumn{1}{c}{ Seleção } & \multicolumn{1}{c}{$1^{\circ}$ Quartil } & \multicolumn{2}{c}{$2^{\circ}$ Quartil } & \multicolumn{2}{c}{$3^{\circ}$ Quartil } & $4^{\circ}$ Quartil \\
\hline \multicolumn{1}{c}{ Categoria } & Sub 17 & Sub 20 & Sub 17 & Sub 20 & Sub 17 & Sub 20 & Sub 17 & Sub 20 \\
\hline Alemanha & $14(67 \%)$ & $7(33 \%)$ & $1(5 \%)$ & $6(29 \%)$ & $4(19 \%)$ & $5(24 \%)$ & $2(10 \%)$ & $3(14 \%)$ \\
Costa Rica & $8(38 \%)$ & $10(48 \%)$ & $6(29 \%)$ & $5(24 \%)$ & $6(29 \%)$ & $3(14 \%)$ & $1(5 \%)$ & $3(14 \%)$ \\
EUA & $9(43 \%)$ & $8(38 \%)$ & $5(24 \%)$ & $7(33 \%)$ & $6(29 \%)$ & $2(10 \%)$ & $1(5 \%)$ & $4(19 \%)$ \\
França & $10(48 \%)$ & $5(24 \%)$ & $4(19 \%)$ & $7(33 \%)$ & $6(29 \%)$ & $3(14 \%)$ & $1(5 \%)$ & $6(29 \%)$ \\
Guiné & $4(19 \%)$ & $7(33 \%)$ & $8(38 \%)$ & $4(19 \%)$ & $6(29 \%)$ & $6(29 \%)$ & $3(14 \%)$ & $4(19 \%)$ \\
Honduras & $9(43 \%)$ & $6(29 \%)$ & $4(19 \%)$ & $4(19 \%)$ & $6(29 \%)$ & $6(29 \%)$ & $2(10 \%)$ & $5(24 \%)$ \\
Inglaterra & $7(33 \%)$ & $6(29 \%)$ & $4(19 \%)$ & $3(14 \%)$ & $8(38 \%)$ & $5(24 \%)$ & $2(10 \%)$ & $7(33 \%)$ \\
Irã & $12(57 \%)$ & $9(43 \%)$ & $3(14 \%)$ & $6(29 \%)$ & $4(19 \%)$ & $4(19 \%)$ & $2(10 \%)$ & $2(10 \%)$ \\
Japão & $2(10 \%)$ & $6(29 \%)$ & $10(48 \%)$ & $7(33 \%)$ & $6(29 \%)$ & $5(24 \%)$ & $3(14 \%)$ & $3(14 \%)$ \\
México & $12(57 \%)$ & $12(57 \%)$ & $6(29 \%)$ & $4(19 \%)$ & $2(10 \%)$ & $4(19 \%)$ & $1(5 \%)$ & $1(5 \%)$ \\
N. Zelândia & $9(43 \%)$ & $7(33 \%)$ & $7(33 \%)$ & $12(57 \%)$ & $4(19 \%)$ & $2(10 \%)$ & $1(5 \%)$ & $0(0 \%)$ \\
\hline
\end{tabular}

\section{DISCUSSÃo}

Por mais que o percentual entre os semestres das duas categorias foram praticamente os mesmos, nota-se uma tendência menor de atletas nos três primeiros meses na categoria sub 20 , assim como um pequeno aumento de atletas no último trimestre também nesta categoria. Esta pequena oscilação vai de encontro com o que propõe Costa, Paula, Coelho, Ferreira e Werneck (2014), que analisou os EIR nos atletas da Copa do Mundo FIFA 2014, afirmando que este fenômeno está presente em todos os continentes, mas que seus efeitos tendem a diminuir entre os atletas de elite. Os achados de Pinto et al. (2012), também analisando categorias sub 17 e sub 20, corroboram com esta ideia, nos mostrando que há uma maior incidência dos EIR nas categorias menores.
As seleções de Alemanha, França, Honduras, Inglaterra, Irã e Nova Zelândia, demonstraram uma queda no número de atletas escolhidos no primeiro trimestre, comparando as duas categorias. Com destaque para Alemanha e França, em que as seleções sub 20 levaram metade dos jogadores neste quartil do que suas equipes sub 17. Estados Unidos e México, não apresentaram diferença no número de jogadores convocados por ambas as seleções neste quartil. Costa Rica, Guiné e Japão este último em especial, apresentaram aumento na quantidade de atletas neste quartil. A seleção sub 20 da Inglaterra foi a única a não ter nenhum atleta nascido em janeiro dentre todas as outras seleções e categorias. O méxico, por exemplo, possui 12 atletas nascidos em janeiro em suas duas seleções, e ao mesmo tempo, apenas 2 
atletas somados nos ultimos quartis de seus plantéis.

Analisando o último quartil, destaca-se a seleção da França, com relação ao aumento no número de atletas selecionados na seleção sub 20 comparados a sub 17 , um aumento de $24 \%$ do total de jogadores do grupo. Essa maior representatividade do último trimestre também ocorreu nas seleções de Costa Rica, Estados Unidos e Honduras e Inglaterra. Alemanha, Guiné, Irã, Japão e México não apresentaram diferença no número de atletas neste quartil. A seleção de Nova Zelândia foi a única do grupo que não teve nenhum atleta nascido nos três últimos meses do ano na categoria sub 20.

Tomamos por base o primeiro e o último quartil para esta análise, pois são os que mais evidenciam os EIR nas equipes, tivemos seleções em que $67 \%$ de um grupo de jogadores, nasceram nos três primeiros meses do ano, e uma seleção que não levou nenhum atleta nascido no último trimestre. Com isso, a tendência de escolha de atletas nascidos no início do ano de competição, não é um critério de escolha. Não é a causa, mas talvez a consequência, ao se buscar no processo de seleção um atleta mais "pronto" acaba por escolher aqueles que possuem suas capacidades físicas e táticas já melhores estruturadas, e coincidentemente ou não, estes são os que possuem maior nível no estágio maturacional. Andrade e Costa (2015) sustentam que atletas de base nascidos no primeiro semestre do ano, possuem vantagens no índice de performance tática defensiva, por exemplo, se comparados aos atletas que nasceram no segundo semestre.

O que não pode ser esquecido, é que se trata de categorias de base, ou seja, nenhum atleta ali presente está "pronto", todos ainda estão em processo de amadurecimento para se chegar ao profissional. Rogel, Alves, França, Vilarinho e Madureira (2007) destaca um estudo realizado com jogadores belgas onde os três primeiros meses do calendário do ano esportivo eram de agosto a outubro, e os jogadores que nasciam neste período tinham maior destaque e maior chance de alcançarem as grandes equipes. A Bélgica mudou o calendário, passando agora seu início para janeiro. O efeito se manteve o mesmo, agora os destaques nascem entre janeiro e março.
Se levarmos em conta que seleções de base fazem parte do processo de formação dos atletas, privilegiar os com maior destaque físico advindos de uma maturação precoce ou vantagens do EIR, em detrimento dos demais, é praticamente "aleijar" o processo de formação, uma vez que tenhamos jovens promissores nas equipes, mas que por consequência da maturação tardia ou de ter um concorrente mais forte, sempre ficará para segundo plano, tendendo a diminuir também sua confiança. Silva, Padilha e Costa (2015) afirma que ao comporem seleções de base, focam apenas no processo de seleção, não no de formação. Analisou seleções sub 20 e profissionais masculinas e femininas, e destacou que os EIR, não se evidenciam nas atletas do sexo feminino, uma vez que o ingresso na modalidade e seleção é mais tardio, nivelando melhor o estágio maturacional das jogadoras.

Este fenômeno está presente em várias modalidades esportivas, sendo mais agudo nas categorias de base. E em cada modalidade, age de maneira diferente, de acordo com a especificidade da modalidade e contexto cultural do local aonde está envolvido. Na natação, por exemplo, Costa, Coelho, Werneck, Paula e Ferreira (2015) analisou 1028 atletas de natação participantes do mundial de esportes aquáticos de 2013, e em seus achados constatou que os EIR não se evidenciaram no sexo masculino, mas em contrapartida no sexo feminino, sim. Diferentemente do que ocorre no futebol.

Este fenômeno negligencia os demais jogadores, e os que se favorecem dele são escolhidos pelos melhores clubes, tendo melhores oportunidades e maior autoestima, em relação aos demais, o que pode levar a grandes falhas no processo de formação esportiva. Jogadores que não se destacam nas categorias de base, tendem a abandonar precocemente $\mathrm{o}$ esporte, representando uma perda de talentos para o futebol, esta é uma das consequências negativas dos EIR, segundo Costa, Cardoso \& Garganta (2014). Sustentando esta afirmação, Ribeiro Jr. et al. (2013) analisou 924 atletas de tênis de campo, identificou o EIR em todas, exceto uma categoria, e apontou que ocorre uma evasão de tenistas nascidos no segundo semestre do ano, por desvantagens maturacionais durante 
o processo de amadurecimento no esporte. Porém, não verificou associação entre idade relativa e desempenho esportivo, o que demonstra que ter as capacidades físicas melhores estruturadas em decorrência da idade, não determinará o sucesso esportivo ao se profissionalizar. Já Rogel et al. (2007) faz uma análise à partir da teoria da prática deliberada, proposta por Ericsson, e cita que além da aptidão esportiva, a participação em uma prática bem estruturada, por um grande período de tempo, melhora as aptidões do atleta, físicas, táticas e psicológicas. Ou seja, quanto mais qualificadas e diversificadas as oportunidades que este atleta tiver em sua formação, melhor ele ficará.

\section{CONCLUSÕES}

Os efeitos foram observados na categoria sub 17, embora não tenha havido diferença entre as categorias, mas houve uma pequena migração no número de atletas que foi selecionado, saindo do primeiro quartil e indo para os três últimos. Conclui-se no presente estudo que o EIR esteve presente nos mundiais da FIFA sub 17 e sub 20 disputados no ano de 2017.

\section{Agradecimentos: \\ A equipe do Laboratório de Metodologia do Ensino dos Esportes (LAMEES).}

\section{Conflito de Interesses:}

Nada a declarar.

\section{Financiamento:}

Nada a declarar.

\section{REFERÊNCIAS}

Andrade, M. \& Costa, I. (2015). Como a eficiência do comportamento tático e a data de nascimento condicionam o desempenho de jogadores de futebol? Revista Brasileira de Educação Física e Esporte, 29(3), 465-473.

Carli, G., Luguetti, C. N., Ré A. H. N. \& Böhme M. T. S. (2009). Efeito da Idade Relativa no Futebol. Revista Brasileira de Ciência E Movimento, 17(3), 2531.

Costa, I. T., Cardoso, F. S. L. \& Garganta, J. O Índice de Desenvolvimento Humano e a Data de Nascimento podem condicionar a ascensão de jogadores de Futebol ao alto nível de rendimento? Revista Motriz, 19(1), 34-45.

Costa, O. G., Coelho, E. M., Werneck, F. Z., Paula, L. V. \& Ferreira, R. M. (2015). Efeito da Idade Relativa em nadadores participantes do mundial de esportes aquáticos Barcelona 2013. Revista da Faculdade de Educação Física da UNICAMP, 13(2), 83-97.

Costa, O. G., Paula, H. L. B., Coelho, E. F., Ferreira, R. M. \& Werneck, F. W. (2014). O Efeito da Idade Relativa: Análise da Copa do Mundo FIFA 2014. Revista Brasileira de Futebol, 7(1), 66-72.

Penna, E. M., Costa, V. T., Ferreira, R. M. \& Moraes, L. C. C. A. (2012). Efeito da Idade Relativa no futsal de base de Minas Gerais. Revista Brasileira de Ciências e Esporte, 34(1), 41-51.

Penna, E. \& Moraes, L. (2010). Efeito relativo da idade em atletas brasileiros de futsal de alto nível. Revista Motriz, 16(3), 658-663.

Pinto, D. et al. 2012. Efeito da idade relativa no Futebol: Análise em jogadores Sub-elite e elite no Brasil. Revista Brasileira de Futebol, 5(1), 24-30.

Rabelo, F. et al. Efeito da Idade Relativa nas categorias do futebol brasileiro: critérios de seleção ou uma tendência populacional? Revista Brasileira de Ciências e Esporte, 38(4), 370-375.

Relação de Atletas da Copa do Mundo FIFA Sub 20 e Sub 17 de 2017. Disponível em: <http://www.fifa.com>. Acesso em: 05 fev. 2018.

Ribeiro jr, E. et al. (2013). O Fenômeno da Idade Relativa em atletas de tênis infanto-juvenil e profissional; Nível de associação com o Ranking da federação Sul-Americana e Mundial. Revista da Educação Física/UEM, 24(3), 371-379.

Rogel, T., Alves, I., França, H., Vilarinho, R. \& Madureira, F. (2007). Efeitos da Idade Relativa na Seleção de Talento no Futebol. Revista Mackenzie de Educação Física e Esporte, 6(3), 171-178.

Silva, D., Padilha, M. \& Costa, I. (2015). O efeito da idade relativa em copas do mundo de futebol masculino e feminino nas categorias sub-20 e profissional. Revista da Educação Física, 26(4), 567572.

Todo o conteúdo da revista Motricidade está licenciado sob a Creative Commons, exceto quando especificado em contrário e nos conteúdos retirados de outras fontes bibliográficas. 